\title{
Comparison of two scores for allocating resources to doctors in deprived areas
}

\author{
Allen Hutchinson, Christopher Foy, Becky Sandhu
}

\begin{abstract}
Current proposals in the general practitioner contract include additional payments to doctors working among deprived populations. The underprivileged area score will be used to identify local authority wards with the greatest levels of deprivation, thus acting as the basis for distributing considerable resources. Two methods of identifying deprived populations - the underprivileged area score and the material deprivation score-were compared to determine whether they result in similar allocation of resources to regions. Financial allocations to regions based on figures derived from the contract differed considerably if the material deprivation score was used instead of the underprivileged area score: Northern and Mersey regions gained over $\mathbf{5 0 \%}$ of their allocation whereas East Anglia, Oxford, and South West Thames regions lost more than $30 \%$ of theirs.

Such differences have considerable implications for doctors working among deprived populations as up to $£ 60 \mathrm{~m}$ each year might be distributed by these payments.
\end{abstract}

\section{Introduction}

One element of the recently published new contract for general practice ${ }^{1}$ concerns the notion of extra payments for doctors working among deprived populations. Such an idea has some attractions whether or not the profession accepts the principle of returning to a greater emphasis on capitation fees as outlined in the NHS review.

General practitioners who work in deprived areas are generally recognised to face more problems of intractable workloads than their colleagues who work in more advantaged areas. Standardised mortality ratios, though a poor proxy for morbidity, ${ }^{3}$ show variations in health among the regions of England and Wales, ${ }^{4}$ with life expectancy for men being considerably worse in the north than in the south. A causal relation between deprivation and health is difficult to refute. When Jarman surveyed the opinions of 2587 general practitioners he found that many doctors regarded social factors such as unemployment, poor housing, and elderly people living alone as having a direct effect on workload (and, by implication on health). ${ }^{5}$ Later, Townsend et al showed a correlation between "material deprivation" and health in the Northern region. ${ }^{6}$

From the perspective of an individual doctor providing care in a disadvantaged area the resulting increase in workload can have the effect of reducing practice income. Thus a doctor with an increased workload for each patient is less able to provide care for a large list of patients than a doctor who works in a more advantaged area. This situation pertains to the current contract but will be reinforced under the new arrangements, which put greater emphasis on payments per person.
Proposals to enhance the income of doctors who work with disadvantaged populations therefore have merit. Appendix B of the contract describes the introduction of a "deprivation supplement" to the basic practice allowance. Doctors will be paid a supplement for each patient on their list who lives in a local authority ward that has been identified as disadvantaged. A sliding scale of payments is proposed, according to the degree of disadvantage ascribed to a ward. Considerable sums of money will be allocated by using the deprivation supplement. To take an extreme case, the categorisation of 2000 of a doctor's patients as severely disadvantaged might increase practice income by as much as $£ 14000$ each year. Given such implications for resources the choice of scoring method to establish which wards are to be regarded as deprived is clearly considerably important.

The contract proposes that wards are ranked according to Jarman's underprivileged area score. ${ }^{5}$ From an organisational perspective this proposal has merit in that the score will already have been computed for the whole of England and the system is ready to implement. The score was not, however, derived specifically to provide a means of determining payment for general practitioners.

In a previous study we showed some differences in the ranking of wards inhabited by patients from a single practice when scored both by the underprivileged area and by the material deprivation score. ${ }^{78}$ In the present paper, we take the issue of differences between these two methods further by comparing the consequences for resource allocation at regional level of each of the scoring methods.

\section{Methods}

Underprivileged area and material deprivation scores were computed from 1981 census data for each of 8478 wards in England. We have used the underprivileged area eight variables score as described by Irving and Rice ${ }^{9}$ and Mays and Bevan. ${ }^{10}$ The eight variables are the percentages of: (1) old age pensioners living alone; (2) children under five years old; (3) people living in single parent households; (4) unskilled workers; (5) unemployed people; (6) people living in overcrowded conditions (more than one person in each room); (7) people who had moved in past year; and (8) people from ethnic minority groups.

These eight census variables were derived from 13 original "social factors" that general practitioners were asked to weight (on a scale of zero to nine) as increasing workload or contributing to pressure of work. Each of the 13 factors was chosen as a result of the analysis of inner city health care undertaken by the London Health Planning Consortium (the Acheson report). To calculate an overall score each of these variables is transformed to approximate to a normal distribution, and the transformed variables are converted to 
standardised scores (with a mean of zero and standard deviation of one). The overall score is a weighted sum of the eight standardised variables, the weights being those derived from Jarman's original survey in 1981.

Material deprivation scores were computed by the method described by Townsend et al. ${ }^{6}$ The score comprises four census variables: (1) the percentage umemployed; (2) the percentage of households without access to a car; (3) the percentage of homes that are not owner occupied; and (4) the percentage of overcrowded homes (more than one person living in each room). The authors used an unweighted sum of standardised scores for these variables; two of the variables required a logarithmic transformation before they were standardised. Townsend et al described their choice of variables at some length. Unemployment was chosen because "it carries implications for a general lack of material resources and the insecurity to which this gives rise. In short, unemployment is the harbinger of other misfortune." In rather similar vein lack of a car was chosen as an indicator of generally low income areas. Not owning a home was also regarded as reflecting lack of wealth as well as income, and the variable concerning overcrowding was selected to give a more general guide to living circumstances and housing conditions.

As the proposals in the new contract are only outlined we had to estimate the sliding scale that would take account of the relative deprivation of a ward. Accordingly, we chose to take the sliding scale proportions to be the most deprived 5\%, 10\%, and $15 \%$ of the distribution of wards in England and Wales. We calculated full deprivation supplement as $£ 7$ per person each year by following the example and calculation on page 32 of the contract. We postulated that the most deprived $5 \%$ of wards would attract the full 17 , the intermediate group in the $5 \%$ to $10 \%$ group would attract $£ 5.50$, and the less deprived group, from $10 \%$ to $15 \%$, would attract $£ 4$ per person.

The distribution of the most deprived $5 \%, 10 \%$, and $15 \%$ of wards has been computed across the 14 regions of England by both scoring methods. Monetary values were attributed to each deprived ward based on its population. Wales and Scotland were excluded from the computation as a modified "Jarman index" will be used to define deprivation. At the time of writing we are unsure how the index will take account of housing and standardised mortality ratios.

\section{Results}

Table I shows the distributions of the most deprived populations in England, scored by both measures. For all but five regions the differences in distributions between the two scoring methods are small. When material deprivation score is used in place of under-

TABLE I - Distribution of most deprived populations in England according to underprivileged area score and material deprivation score with cut off parts of $5 \%, 10 \%$, and $15 \%$

\begin{tabular}{lrrrrrrrr}
\hline & \multicolumn{3}{c}{ Underprivilege area score } & & \multicolumn{2}{c}{ Material deprivation score } \\
\cline { 2 - 5 } \cline { 7 - 8 } Region & \multicolumn{1}{c}{$5 \%$} & $5-10 \%$ & $10-15 \%$ & & $5 \%$ & $5-10 \%$ & $10-15 \%$ \\
\hline Northern & 300274 & 245143 & 284109 & & 572786 & 437048 & 427156 \\
Yorkshire & 430618 & 395330 & 260723 & & 317168 & 316427 & 387185 \\
Trent & 323859 & 228637 & 196953 & & 260991 & 354571 & 387206 \\
East Anglia & 41296 & 53436 & 100947 & & & 53120 & 107129 \\
North West Thames & 315389 & 312981 & 317800 & & 277960 & 203201 & 207532 \\
North East Thames & 684604 & 438272 & 257296 & & 584077 & 364611 & 356021 \\
South East Thames & 416486 & 370303 & 242459 & & 334763 & 292724 & 236490 \\
South West Thames & 44606 & 209385 & 119318 & & 33692 & 78874 & 144071 \\
Wessex & 49235 & 83825 & 69438 & & 34775 & 74701 & 73214 \\
Oxford & 57991 & 142175 & 149874 & & 27895 & 62008 & 128040 \\
South Western & 44282 & 72372 & 157250 & & 31605 & 68519 & 117221 \\
West Midland & 442836 & 378296 & 639812 & & 521227 & & 491687 & 545859 \\
Mersey & 218872 & 244647 & 244294 & & 426473 & 327020 & 196692 \\
North Western & 516848 & 465714 & 413840 & & 463435 & 397471 & 270955 \\
\hline England & 3887196 & 3640516 & 3454113 & & 3886847 & 3521982 & 3584771 \\
& & & & & & & &
\end{tabular}

privileged area score, however, the numbers of wards classed as being in the most deprived 5\% show substantial increases for the northern and Mersey regions (almost twice as many wards) with quite substantial reductions in the number of deprived wards for North East Thames, South East Thames, and North Western regions. Furthermore, within the most deprived $5 \%$ (424) of the wards classified by the material deprivation score $29(6 \cdot 8 \%)$ are not classified as so by the underprivileged area score. Of the most deprived $5 \%$ of the underprivileged area scored wards, however, only $10(2 \cdot 4 \%)$ are not selected by the material deprivation score. This may be a further indication that the two scores are measuring different aspects of deprivation.

Table II shows the financial impact of the different effects of the two scoring methods on each region.

TABLE II-Allocation to regions of deprivation supplement ( $£$ m) by underprivileged area score and material deprivation score

\begin{tabular}{lcc}
\hline Region & $\begin{array}{c}\text { Underprivileged area } \\
\text { score }\end{array}$ & $\begin{array}{c}\text { Material deprivation } \\
\text { score }\end{array}$ \\
\hline Northern & 4.59 & $8 \cdot 12$ \\
Yorkshire & 6.23 & 5.51 \\
Trent & 4.31 & $5 \cdot 33$ \\
East Anglia & 0.99 & 0.72 \\
North West Thames & $5 \cdot 20$ & 3.89 \\
North East Thames & 8.23 & 7.52 \\
South East Thames & 5.92 & 4.90 \\
South West Thames & 1.94 & 1.25 \\
Wessex & 1.08 & 0.95 \\
Oxford & 1.79 & 1.05 \\
South Western & 1.34 & 1.07 \\
West Midland & 7.74 & 8.54 \\
Mersey & 3.85 & 5.57 \\
North Western & 7.83 & 6.51 \\
\hline England & 61.04 & 60.93 \\
\end{tabular}

Although the total number of residents living in the most deprived $15 \%$ of the distribution is remarkably similar for each scoring method $(10982000$ by the underprivileged area score and 10994000 by the material deprivation score), considerable differences in populations occur at the regional level owing to the differing numbers and populations of wards selected. These differences are even more pronounced when the financial effects are considered by using the capitation fees postulated above. As the overall populations of the deprived wards in England for each scoring method are virtually identical the choice of method has no overall financial effect. Within an overall sum of $£ 60 \mathrm{~m}$, however, some regions gain considerably under the material deprivation score compared with under the underprivileged area score whereas others lose appreciable amounts. Taking the full $£ 7$ supplement alone Mersey region gets almost twice as much whereas Oxford region loses almost half and East Anglia attracts no funding.

\section{Discussion}

Neither of the two scoring methods was originally conceived as a means of paying doctors. In effect the two methods measure different aspects of the deprivation problem: the material deprivation score is a measure of deprivation whereas the underprivileged area score is a general practitioner weighted opinion on the effect of deprivation on workload. The arguments for and against the appropriateness of each of the scoring methods under given circumstances have been presented by several authors, for example Mays and Bevan. ${ }^{10}$ Also, we have shown previously how the two scoring methods provide differing results in the ranking of wards domiciled by the patients of one general practice. $^{78}$

From the perspective of doctors' income it could be argued that to use a score based on doctors' own 
opinions - for example, the underprivileged area score - would be undesirable in principle. Furthermore, the new contract will provide additional resources for health surveillance for children under five years and elderly people over 75 , together with a weighting per person for people aged 65 and over. Thus two of the underprivileged area variables are already to some extent provided for in the new contract. Additionally, the variables reflecting the extent of unemployment and proportion of unskilled workers are closely linked whereas mobility is not only the prerogative of disadvantaged families.

By using only four variables without weighting the material deprivation score has the advantage of being more sharply focused on deprivation. These features initially drew us to comparing the two methods in one practice, and the variability of the results led us to question whether using underprivileged area score rather than material deprivation score was appropriate for determining deprivation supplements. A further advantage of the material deprivation score is that Townsend et al have shown a positive correlation between material deprivation and an "overall health index" comprising the three variables: (1) standardised mortality ratio of people aged $0-64 ;(2)$ percentage of low birth weights; and (3) percentage permanently sick. ${ }^{6}$

The first two of these variables have the advantage of being updated annually. Though we acknowledge that standardised mortality ratios are poor proxies for morbidity, there may be advantage in using a deprivation score that has a proved correlation with a measure of health. Clearly there are some considerable differences in allocation of deprivation supplements to regions depending on which scoring method is used, again raising the question of the choice of method. Indeed, it may be that neither is the most appropriate as they both depend on decennial census data. In 1993 the supplement will still be based on data collected in April 1981, and we share Carr-Hill's concerns about the validity of out of date data. ${ }^{12}$ Additionally, a local authority ward is quite a large unit both in absolute terms, with populations over 5000 on average, and in relation to a general practice catchment area. We have shown previously how census enumeration districts with an average population under 500 can show quite severe pockets of deprivation that are not apparent in the overall ward score. ${ }^{78}$ A person labelled "deprived" can change state with a change of domicile across a boundary. Instant "deprivation" or "non-deprivation" is therefore created.

Depending on which score is used and which cut off points are used on the frequency distribution of deprivation (we considered $5 \%, 10 \%$, and $15 \%$ as plausible) the effect on regional deprivation supplement budgets can be quite substantial. Even in the 5\% most disadvantaged of the wards general practitioners working in Mersey region would gain an extra $£ 1.4 \mathrm{~m}$ each year if material deprivation scores rather than underprivileged area scores were used. If each general practitioner had 1000 of these additional people on his or her list 200 doctors in Mersey would each gain $£ 7000$ each year at the expense of losing regions.

This paper raises more questions than it answers. Given the differences between the two scoring methods, there are winners and losers in every region. We are unable to firmly recommend one of the methods as the most appropriate, although we have indicated that, on balance, there may be a case for using the material deprivation score rather than underprivileged area score. Further work clearly needs to be commissioned to find an indicator of deprivation that is available more than once every decade. If the underprivileged area score is to be used a review of the weightings applied to the scale in 1991 will be required as the original weightings ${ }^{5}$ will also be 10 years old and possibly less appropriate.

Payments to doctors working in deprived areas will redistribute substantial sums of money. The methods used in allocating these scarce resources should be considered carefully, and further research is necessary to ensure that they are allocated appropriately.

We acknowledge Crown copyright in the use of 1981 census data and thank the centre for urban and regional development studies at the University of Newcastle upon Tyne for help with the handling of census data. We also thank the Department of Health for supporting this work through resources provided within the health care research unit.

1 Health Departments of Great Britain. General practice in the National Healt Service. The 1990 contract London: HMSO, 1989.

2 Secretaries of State for Health, Wales, Northern Ireland, and Scotland. Working for patients. London: HMSO, 1989. (Cmnd 555.

3 Ashley J, McLachlan G. Mortal or morbid. London: Nuffield Provincia Hospitals Trust, 1985

4 Whitehead M. The health divide: inequalities in health in the 1980's. London: Health Education Authority, 1987.

6 Jarman B. Identification of underprivileged areas. Br Med f 1983;286:1705-9. 6 Townsend P, Phillimore P, Beattie A. Health and deprivation-inequality and the north. London: Croom Helm, 1988.

7 Hutchinson A, Foy C, Smyth J. Providing census data for general practice. Feasibility. $7 R$ Coll Gen Pract 1987:37:448-50.

8 Foy C, Hutchinson A, Smyth J. Providing census data for general practice. Usefulness. $f R$ Coll Gen Pract 1987:37:451

9 Irving D, Rice P. Information for health services planning from the 1981 census. London: London School of Economics, 1984

10 Mays N, Bevan G. Resource allocation in the health service. London: Bedford Square Press, 1987. (Occasional paper on social administration 81.)

11 London Health Planning Consortium Primary Health Care Study Group. Primary health care in inner London. London: Department of Health and Social Security, 1981.

12 Carr-Hill R. Revising the RAWP formula: indexing deprivation and modelling demand. Discussion paper 4I. York: Centre for Health Economics, 1988.

(Accepted 14 September 1989)

\section{ONE HUNDRED YEARS AGO}

The few words of feeble protest which I timidly uttered last week on the tedious tyranny of post-prandial prosiness at medical dinners have, I find, been taken in good part. The letters which I have received utter one long sigh of retrospective suffering seasoned by prospective satisfaction at the hope of future relief. I was not surprised at a little good-tempered banter on the subject at the very successful dinner of the Metropolitan Counties Branch, but the good effects were visible, and were much appreciated. The "toast list" offered the glorious prospect of seventeen speeches; but Dr. Ord gave the loyal toasts in the true military style, which I ventured to commend, heartily and cordially, but without speeches. There were only two songs, which were quite enough, an excellent band having played al through the dinner; and the speaking, which was throughout pointed and brief, was got through in gallant style in an hour and a half. The toast list, however, was felt to be far too long, and several of the speakers complained of having "no notice." One speaker complained good-naturedly that it was hard to be expected to be "witty" without possessing the natural gift. I had suggested, however, many other alternatives, and, in the absence of any other kind of humour, there remains the "soul of wit," which is at every man's command. "I tried above all things," said an eloquent but longwinded preacher to the celebrated Robert Hall, who was sitting among his congregation, "not to be tedious;" to which came the candid reply, "Ah, but you were tedious." That is apt to be the fate of the most eloquent orators after dinner, if they are lengthy. The Yankee explanation of why the lions did not eat Daniel when he intruded in their den was told dramatically and at length on Friday evening. Briefly, it was because they recoiled before the prospect of being required to make "an after-dinner speech." It is an excellent moral. Our lions are expected nowadays to make a great many speeches, and do not always do it well. To roar like a sucking dove is a rare accomplishment.

(British Medical Fournal 1889;ii:92) 